\title{
Genetically Engineered S and F1C Fimbriae Differ in Their Contribution to Adherence of Escherichia coli to Cultured Renal Tubular Cells
}

\author{
R. MARRE, ${ }^{1 *}$ B. KREFT, ${ }^{1}$ AND J. HACKER ${ }^{2}$ \\ Institut für Medizinische Mikrobiologie, Universität Lübeck, Ratzeburger Allee 160, D-2400 Lübeck, ${ }^{1}$ and Institut für \\ Genetik und Mikrobiologie, Universitat Würzburg, D-8700 Würzburg, ${ }^{2}$ Federal Republic of Germany \\ Received 4 May 1990/Accepted 18 July 1990 \\ Escherichia coli K-12 strains producing S-fimbrial adhesins, F1C fimbriae, and mutagenized fimbriae were \\ tested in a binding assay with a renal tubular cell line. S-fimbrial adhesins and F1C fimbriae mediated binding \\ to tubular cells. The SfaA, SfaG, and SfaS subunits of $S$ fimbriae contributed to attachment. Site-specific \\ mutations in the sfaS gene reduced binding. The inhibition profile of F1C fimbriae resembled that of S fimbriae.
}

The adherence of bacteria to receptors on eucaryotic cells is regarded as the first step in infectious diseases. It is mediated by adhesins, which may be located on the tips of the fimbriae, filamentous protein appendages of up to $2 \mu \mathrm{m}$ in length (6). Different fimbriae have been identified in Escherichia coli causing extraintestinal infections, such as urinary tract infections and newborn meningitis $(7,16)$. S-fimbrial adhesins expressed by strains causing newborn meningitis or urinary tract infections attach to glycoproteins terminating with $\alpha$-sialyl-acid-2-3- $\beta$-galactosamine (14). F1C fimbriae mediate no hemagglutinating activity, and their binding specificity has not been identified. The determinants coding for S and F1C fimbriae belong to one adhesin family and are genetically and immunologically related $(11,12,19)$. The fimbrial adhesin complexes of $S$ and F1C fimbriae consist of major and minor protein subunits $(8,11)$. For $S$-fimbrial adhesins it has been shown recently that the minor subunit protein SfaS mediates hemagglutinating activity (18).

In this report, we present data on the tubular cell adherence of $E$. coli cells harboring wild-type and mutagenized gene determinants of $S$ and F1C fimbriae. Inhibition studies were performed to gain preliminary information on the receptor structure specific for F1C fimbriae.

All $E$. coli strains tested were grown on Loeb agar supplemented with antibiotics if appropriate. The recombinant DNAs are indicated in Fig. 1. E. coli HB101 (pANN801-13) produced the S-fimbrial adhesin complex (1, 4). In strains HB101(pANN801-1), HB101(pANN801-1320), HB101 (pANN801-1321), and HB101 (pANN801-13/Tn5-033), the major and minor subunit genes $s f a A, s f a G$, sfaS, and $s f a H$, respectively, were mutagenized separately $(4,18)$. The clones HB101(pANN801-116), HB101(pANN801-118), and HB101(pANN801-122) carry site-specific mutations in the gene sfaS coding for the sialic acid-binding adhesin (9). Strain HB101(pPIL110-54) codes for F1C fimbriae, and strain HB101 (pANN801-E4) as well as strain HB101 (pANN801-C25) produce F1C-fimbrial-S-fimbrial hybrid adhesins $(11,19)$. All recombinant plasmids were transformed in the $E$. coli $\mathrm{K}-12$ strain $\mathrm{HB} 101$.

Fimbriation of the strains was tested by electron microscopy and by an enzyme-linked immunosorbent assay (ELISA) with fimbria-specific monoclonal antibodies as de-

\footnotetext{
* Corresponding author.
}

scribed previously $(2,4,8,17)$. Hemagglutination was tested in microtiter plates by a quantitative assay as described previously $(9,18)$. Antisera against heat-killed $E$. coli K-12 were produced in rabbits by intravenous injections of 50 to $200 \mu \mathrm{g}$ of bacteria on days $0,4,7,11,16,52$, and 62 .

Adherence to the renal tubular cell line LLC-PK 1 (pig kidney) (5) (ATCC CL 101) was determined by an ELISA basically as described by Fujita et al. (3) and Ofek et al. (10) with some modifications. The cells were placed in wells of a 96-well plate (Linbro; Flow Laboratories). When the cells had grown to a confluent monolayer without gaps, the medium was removed and $1.25 \%$ glutaraldehyde was added for $15 \mathrm{~min}$ at ambient temperature. After washing with phosphate-buffered saline ( $\mathrm{pH}$ 7.2) and blocking with bovine serum albumin (Serva, Heidelberg, Federal Republic of Germany), the respective $E$. coli strains were added. After incubation $\left(1 \mathrm{~h}, 37^{\circ} \mathrm{C}\right)$, the nonadherent bacteria were removed by washing with phosphate-buffered saline. Afterwards, $100 \mu \mathrm{l}$ of diluted $E$. coli antiserum was added, and the mixture was incubated for $1 \mathrm{~h}$ at $37^{\circ} \mathrm{C}$, followed by five washings and the addition of alkaline phosphatase-conjugated swine anti-rabbit immunoglobulin G (Dako, Hamburg, Federal Republic of Germany). Finally, after five washings, alkaline phosphatase substrate $(1.0 \mathrm{mg} / \mathrm{ml}$; Sigma Chemie, Deisenhofen, Federal Republic of Germany) was added; after incubation, extinction was measured with an ELISA reader (Behring, Marburg, Federal Republic of Germany). Each strain was tested in at least three separate trials. In each trial, 24 determinations of cell adherence were performed in parallel.

The controls were treated in the same manner, except that bacteria were not added. The adherence of bacteria to the microtiter plate plastic was near zero.

Data for control groups were transformed to zero, and the other data were treated accordingly. Data were normally distributed. The mean values \pm standard deviations for at least 72 single values were calculated. Statistical evaluation was performed by the $t$ test (15).

For inhibition studies of F1C-fimbriated $E$. coli, potential inhibitors (Sigma Chemical Co., St. Louis, Mo.) were added to the bacterial suspension, and the mixture was placed in microtiter plates. For receptor-destroying experiments, neuraminidase $(0.5$ to $10 \mathrm{mU} / \mathrm{ml})$ (E. Merck, AG, Darmstadt, Federal Republic of Germany) was dissolved in M199 (Flow Laboratories, Meckenheim, Federal Republic of Germany) 


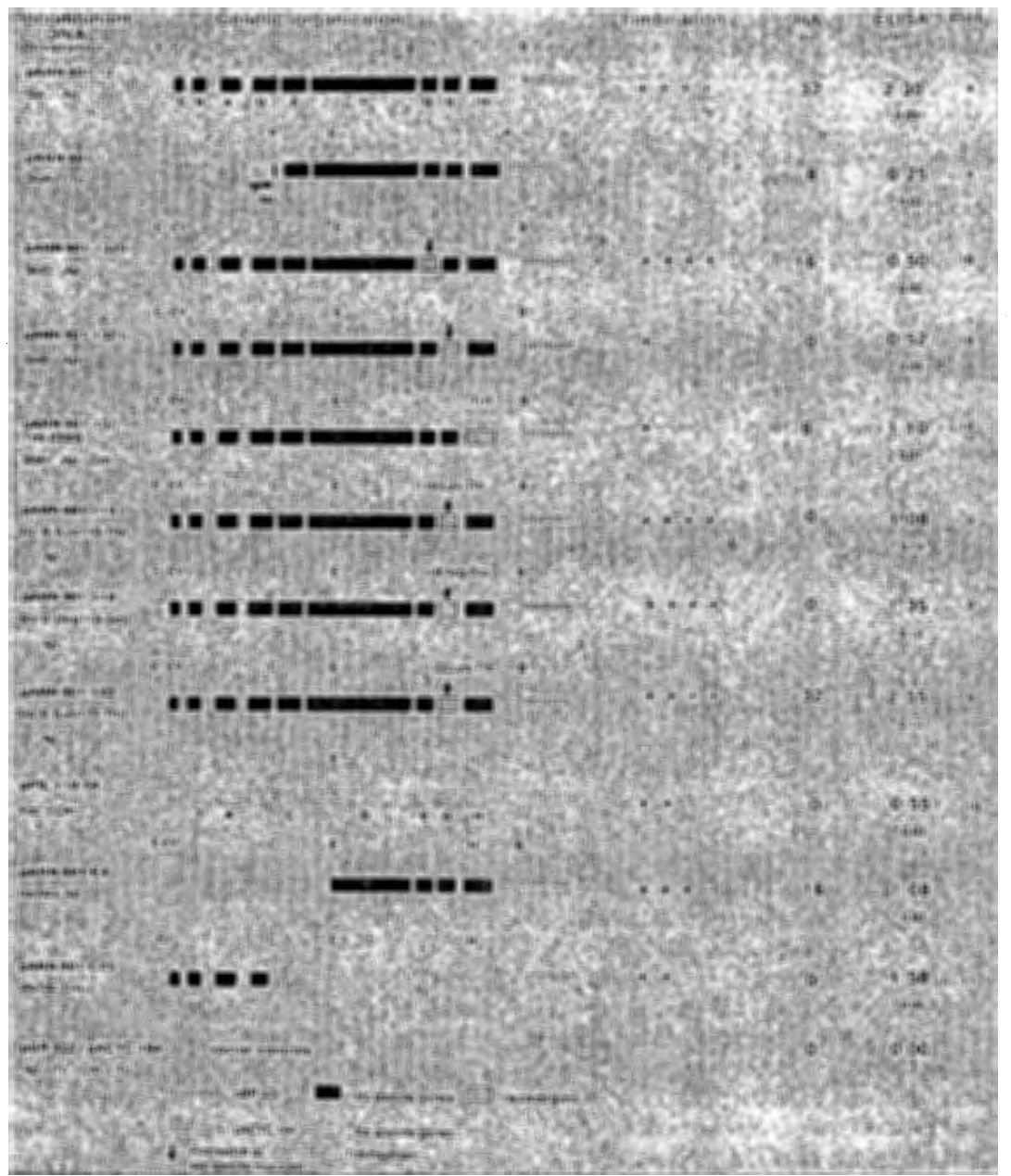

FIG. 1. ELISA units (mean \pm standard deviation) for $E$. coli K-12 clones carrying recombinant DNAs coding for S-fimbrial adhesin (sfa), F1C fimbriae $(f o c)$, S-fimbrial-F1C-fimbrial hybrid adhesins, and mutagenized S-fimbrial adhesin complexes. The ELISA were carried out

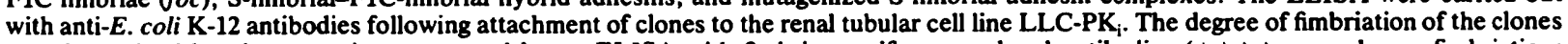
was determined by electron microscopy and by an ELISA with fimbria-specific monoclonal antibodies $(++++$, very heavy fimbriation; +++ , heavy fimbriation; ++ , intermediate fimbriation; + , low fimbriation; - , no fimbriation). Hemagglutination (HA) was carried out in microtiter plates $(9,18)$. HB101 (pBR322) was used as a control. The genetic maps of the DNAs used are indicated. The letters below the black boxes represent sfa-specific genes, and the letters below the open boxes represent foc-specific genes. Ap ${ }^{r}$, Resistance to ampicillin; $\mathbf{C m}^{r}$, resistance to chloramphenicol; Tc ${ }^{\mathrm{r}}$, resistance to tetracycline. E, EcoRI; Ev, EcoRV; C, ClaI; H, HindIII; B, BamHI; P, PstI.

without fetal calf serum, $100 \mu$ was placed in each well, and the mixture was incubated for 30 and 60 min. The remaining steps were identical to those described above. Control experiments were done without neuraminidase and without any other potential inhibitors.

Strain HB101(pANN801-13), which produced the wildtype S-fimbrial adhesin complex, showed distinct binding to renal tubular cells (Fig. 1). Mutations in the genes sfaA, $s f a G$, and $s f a S$ were associated with a dramatic reduction in cell adherence. A mutation in the gene coding for the minor subunit cSfaH affected adherence considerably less, a result which may have been due to the reduction in the fimbriation of strain HB101(pANN801-13/Tn5-033) as compared with that of strain HB101(pANN801-13). The data, however, clearly show that the major subunit protein SfaA and the minor subunit proteins SfaG and SfaS contribute to the adherence of $S$ fimbriae to tubular cells.
Site-specific mutations were introduced into gene $s f a S$ coding for the S-fimbrial adhesin. The mutations resulted in a change in the amino acid sequence of the S-fimbrial adhesin at the C-terminal end. We found that an exchange of lysine for threonine at position 122 [HB101(pANN801-122)], which had no effect on hemagglutination (9), also did not reduce binding to renal tubular cells, while an exchange of lysine for threonine at position 116 [HB101(pANN801-116)] and an exchange of arginine for serine at position 118 [HB101(pANN801-118)] hindered adherence to renal tubular cells significantly but did not reduce binding completely. These mutations, however, reduced hemagglutination to below the lower limit of detection (9).

The level of binding of $E$. coli HB101(pPIL110-54) producing F1C fimbriae to tubular cells was lower than that of $S$-fimbriated strain HB101(pANN801-13). Hybrids of $s f a$ and $f o c$ genes affected binding. When the $s f a$-specific sequences 
TABLE 1. Inhibition of $E$. coli HB101(pPIL110-54) expressing F1C fimbriae and HB101(pANN801-13) expressing S fimbriae

\begin{tabular}{lcc}
\hline \multirow{2}{*}{ Inhibitor } & \multicolumn{2}{c}{ Concn (mmol) of ${ }^{a}:$} \\
\cline { 2 - 3 } & pPIL110-54 & pANN801-13 \\
\hline D-(+)-Glucose & 100 & ND $^{b}$ \\
D-(+)-Galactose & 100 & ND \\
$\alpha$-Lactose & 100 & ND \\
$\beta$-D-Fructose & 100 & ND \\
$\alpha$-D-Fucose & 100 & ND \\
$\alpha$-L-Fucose & 100 & ND \\
$N$-Acetyl-D-glucosamine & 100 & 100 \\
$N$-Acetyl-D-galactosamine & 100 & 100 \\
$N$-Acetyl-lactosamine & 25 & 100 \\
$N$-Acetyl-neuraminic acid & 100 & 25 \\
$N$-Acetyl-neuraminyl lactose & 100 & 25 \\
$N$-Acetyl-muraminic acid & 100 & ND \\
$\alpha$-Methyl-mannoside & 100 & ND \\
\hline a Concentration leading to a significant $(P$ & $0.05)$ decrease in extinction.
\end{tabular}

ND, Not done.

carrying the $\mathrm{S}$ fimbrilin-encoding gene $s f a A$ were fused to sequences representing the distal region of the foc gene cluster, the resulting plasmid, pANN801-C25, coded for a higher level of binding than did that containing the genetic determinant for F1C fimbriae. The second hybrid cluster plasmid, pANN801-E4, representing the proximal region of foc coding for the structural protein FocA and the distal region of the $s f a$ gene cluster, also enhanced binding significantly, but less so than did plasmid pANN801-C25.

Since $E$. coli expressing F1C fimbriae bound avidly to tubular cells, it was possible to determine the inhibition profile to obtain information on the receptor structure. For inhibition studies, several carbohydrate and neuraminidase treatments were used (Table 1). Pretreatment of the tubular cells with neuraminidase $(10 \mathrm{mU})$ for $60 \mathrm{~min}$ significantly reduced the adherence of strains HB101(pPIL110-54) and HB101(pANN801-13), while a 30-min pretreatment inhibited the binding only of the strain expressing $S$ fimbriae. Furthermore, treatment with $N$-acetyl-neuraminic acid $(100 \mathrm{mmol})$, $N$-acetyl-neuraminyl lactose $(100 \mathrm{mmol})$, and $N$-acetyl-lactosamine $(25 \mathrm{mmol})$ led to reduced binding of F1C fimbriaexpressing strains to the tested cell line, but several other substances had no effect (Table 1). The inhibition profile for $E$. coli $\mathrm{HB101}$ (pANN801-13) producing $S$ fimbriae was quantitatively different from that of $E$. coli HB101(pPIL110-54). $N$-Acetyl-lactosamine was a weaker inhibitor, while $N$-acetyl-neuraminyl lactose and $N$-acetyl-neuraminic acid were stronger inhibitors.

The ELISA offered the possibility of quantifying the adherence of whole bacteria producing different adhesin proteins. Furthermore, the in vitro system used allowed differentiation among the properties of the adhesins of the different strains. Although the tubular cell line was derived from the proximal tubulus of a pig, the binding characteristics were comparable to those found by Virkola et al. (20) with renal tissue from humans and isolated fimbriae. Our data indicate that the $S$ fimbrillin SfaA, the S-fimbrial adhesin SfaS, and the minor subunit SfaG contribute to attachment to tubular cells.

It is evident that the SfaS-negative, hemagglutinationnegative clone still retained significant binding capacity. The lack of hemagglutination was probably not due to an insufficient sensitivity of the assay, since a strain with similar adherence values in the ELISA [HB101(pANN801-13/Tn5033)] was able to hemagglutinate. Our data suggest that another receptor structure which is not identical to the SfaS-specific substance may exist. Parkkinen et al. (13) also found that mutagenized S fimbriae lacking SfaS still adhered to endothelial cells and that inhibition with sialyl-lactose decreased but did not abolish the binding of $\mathbf{S}$ fimbriae. For this alternative binding capacity, which is independent from the SfaS-mediated adherence, the major subunit protein $\mathrm{SfaA}$ and the minor subunit protein $\mathrm{SfaG}$ may be responsible, since mutations of these subunits resulted in a decrease in binding. The nature of the corresponding receptor is unknown, but it can be concluded that endothelial cells and tubular cells express structures which mediate SfaS-independent binding of S-fimbrial adhesins. The existence of a second, SfaS-independent attachment protein resembles the situation for $\mathbf{P}$ fimbriae which, in addition to the wellcharacterized $P$ adhesin protein, PapG, possess a second, lectin-independent adherence factor binding to fibronectin (21).

Site-specific mutagenesis led to a loss of hemagglutination when the lysine at position 116 was replaced by threonine and when the arginine at position 118 was replaced by serine. In our adherence test system, adherence to tubular cells was reduced in parallel with hemagglutination; however, residual adherence due to alternative binding of the S-fimbrial adhesin complex could still be observed. In addition, differences in the amounts of the fimbrial adhesin complex may have influenced the binding properties of S-fimbriated strains (Fig. 1). This may also be true for binding of F1C fimbriae.

The adherence of F1C fimbriae offered the possibility of studying the inhibition profile and thus gain insight into the receptor structure, which is unknown because of the lack of a suitable test system, (because F1C fimbriae do not mediate hemagglutination and do not bind to urinary tract sediment cells) $(19,20)$. The inhibition profile resembled that of $\mathrm{S}$ fimbriae, since $N$-acetyl-neuraminic acid, neuraminidase, $N$-acetyl-neuraminyl lactose, and $N$-acetyl-lactosamine were inhibitors. However, the concentrations of the sugars and the lengths of incubation of neuraminidase needed for inhibition differed. It is not clear from these findings why F1C fimbriae have no hemagglutination activity. It may be that the F1C receptors on erythrocytes are either not present in sufficient amounts or not accessible on the erythrocyte surface membrane. In general, our data confirm the fact that F1C fimbriae and S fimbriae belong to the same family of fimbrial adhesins, related genetically, immunologically, and functionally.

We thank M. Ott, Institut für Genetik und Mikrobiologie, Universitat Würzburg, Würzburg, Federal Republic of Germany, for helpful discussions and Irma van Die, Department of Molecular Cell Biology, University of Utrecht, Utrecht, The Netherlands, for providing plasmid pPIL110-54.

This work was supported by the Deutsche Forschungsgemeinschaft (grants Ha 1434/1-5 and Ma 864/3-1) and by the Fonds der Chemischen Industrie.

\section{LITERATURE CITED}

1. Bolivar, F., R. L. Rodriguez, P. J. Greene, M. C. Betlach, H. L. Heyneker, and H. W. Boyer. 1977. Construction and characterization of new cloning vehicles. II. A multipurpose cloning system. Gene 2:95-113.

2. Boylan, M., D. C. Coleman, and C. J. Smyth. 1987. Molecular cloning and characterization of the genetic determinant encoding CS3 fimbriae of the enterotoxigenic Escherichia coli. Microb. Pathog. 2:195-209.

3. Fujita, K., T. Yamamoto, T. Yokota, and R. Kitagawa. 1989. In vitro adherence of type 1-fimbriated uropathogenic Escherichia coli to human ureteral mucosa. Infect. Immun. 57:2574-2579. 
4. Hacker, J., G. Schmidt, C. Hughes, S. Knapp, M. Marget, and W. Goebel. 1985. Cloning and characterization of genes involved in production of mannose-resistant, neuraminidase-susceptible (X) fimbriae from a uropathogenic 06:K15:H31 Escherichia coli strain. Infect. Immun. 47:434-440.

5. Hull, R. N., W. R. Cherry, and L. W. Weaver. 1976. The origin

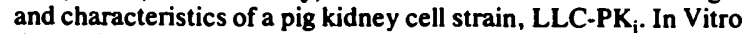
(Rockville) 12:670-677.

6. Klemm, P. 1985. Fimbrial adhesins. Rev. Infect. Dis. 7:321-340.

7. Marre, R., J. Hacker, W. Henkel, and W. Goebel. 1987. Contribution of cloned virulence factors from uropathogenic Escherichia coli strains to nephropathogenicity in an experimental rat pyelonephritis model. Infect. Immun. 51:761-767.

8. Moch, T., H. Hoschützky, J. Hacker, K. D. Kroncke, and K. Jann. 1987. Isolation and characterization of the $\alpha$-sialyl- $\beta-2,3-$ galactosyl-specific adhesin from fimbriated Escherichia coli. Proc. Natl. Acad. Sci. USA 84:3462-3466.

9. Morschhäuser, J., H. Hoschützky, K. Jann, and J. Hacker. 1990. Functional analysis of the sialic acid-binding adhesin SfaS of pathogenic Escherichia coli by site-specific mutagenesis. Infect. Immun. 58:2133-2138.

10. Ofek, I., H. S. Courtney, D. M. Schifferli, and E. H. Beachey. 1986. Enzyme-linked immunosorbent assay for adherence of bacteria to animal cells. J. Clin. Microbiol. 24:512-516.

11. Ott, M., H. Hoschützky, K. Jann, I. van Die, and J. Hacker. 1988. Gene clusters for S fimbrial adhesin ( $s f a)$ and F1C fimbriae (foc) of Escherichia coli: comparative aspects of structure and function. J. Bacteriol. 170:3983-3990.

12. Ott, M., T. Schmoll, W. Goebel, I. Van Die, and J: Hacker. 1987 Comparison of the genetic determinant coding for the S-fimbrial adhesin $(s f a)$ of Escherichia coli to other chromosomally encoded fimbrial determinants. Infect. Immun. 55:1940-1943.

13. Parkkinen, J., A. Ristimäki, and B. Westerlund. 1989. Binding of Escherichia coli $\mathrm{S}$ fimbriae to cultured human endothelial cells.
Infect. Immun. 57:2256-2259.

14. Parkkinen, J., G. N. Rogers, T. Korhonen, W. Dahr, and J. Finne. 1986. Identification of the O-linked sialyloligosaccharides of glycophorin $A$ as the erythrocyte receptors for S-fimbriated Escherichia coli. Infect. Immun. 54:37-42.

15. Sachs, L. 1984. Angewandte Statistik. Springer Verlag KG, Berlin.

16. Saukkonen, K. M. J., B. Nowicki, and M. Leinonen. 1988. Role of type 1 and $S$ fimbriae in the pathogenesis of Escherichia coli O18:K1 bacteremia and meningitis in the infant rat. Infect. Immun. 56:892-897.

17. Schmitz, S., C. Abe, I. Moser, I. Grskov, F. Grikov, B. Jann, and K. Jann. 1986. Monoclonal antibodies against the nonhemagglutinating fimbrial antigen 1C (pseudotype 1) of Escherichia coli. Infect. Immun. 51:54-59.

18. Schmoll, T., H. Hoschützky, J. Morschăuser, F. Lottspeich, K. Jann, and J. Hacker. 1989. Analysis of genes coding for the sialic acid-binding adhesin and two other minor fimbrial subunits of the S-fimbrial adhesin determinant of Escherichia coli. Mol. Microbiol. 3:1735-1744

19. van Die, I., R. vanGefien, W. Hoekstra, and H. Bergmans. 1985 Type 1C fimbriae of a uropathogenic Escherichia coli strain: cloning and characterization of the genes involved in the expression of the $1 \mathrm{C}$ antigen and nucleotide sequence of the subunit gene. Gene 34:187-196

20. Virkola, R., B. Westerlund, H. Holthơfer, J. Parkkinen, M. Kekomaki, and T. K. Korhonen. 1988. Binding characteristics of Escherichia coli adhesins in human urinary bladder. Infect. Immun. 56:2615-2622.

21. Westerlund, B., P. Kuusela, T. Vartio, I. van Die, and T. K. Korhonen. 1989. A novel lectin-independent interaction of $\mathbf{P}$ fimbriae of Escherichia coli with immobilized fibronectin. FEBS Lett. 243:199-204. 